\title{
Hemoglobin Targets versus Oxygen Delivery: Is It Time for a New Paradigm?
}

\author{
Charles J. Diskin \\ Auburn University, Opelika, Ala., USA
}

$$
\text { Sir, }
$$

I would like to congratulate Dr. Fishbane for his excellent review of the recent advances in our understanding of hemoglobin targets [1]; however, even as his review reached publication, another metaanalysis concluded that higher hemoglobin concentrations are associated with increased mortality [2]. I would like to suggest that perhaps the targeting of hemoglobin levels might be the wrong approach. What we really should care about is oxygen delivery. Hemoglobin is merely a vehicle to achieve that delivery and the amount of vehicle necessary may change depending upon the clinical situation. As Dr. Fishbane notes, it is usually tissue hypoxia that normally regulates hemoglobin concentrations, but with exogenous administration of recombinant erythropoietin, that regulation is lost. For many years we have known that normal subjects develop higher hemoglobin concentrations at greater altitudes to facilitate oxygen delivery [3], yet we have the same hemoglobin targets for the dialysis patients of New Orleans as for those of the mountains of Colorado. Similarly, we know that acidosis (the Bohr effect) and hyperphosphatemia [4] shift the oxygen-hemoglobin dissociation curve to allow more oxygen delivery, yet we make no accommodation for these factors despite the fact that they are frequently quite abnormal in the dialysis population. We recently found that acido- sis and hyperphosphatemia independent of parathyroid hormone concentrations were the principle factors associated with erythropoietin resistance in our population [5]. One possible explanation would be the speculation that the increased oxygen delivery may be associated with downregulation of erythropoietin receptors, since down-regulation of erythropoietin production is not possible. Perhaps it is time for a new paradigm and maybe we should look to create a new equation that accounts not only for the hemoglobin concentration but also for the hemoglobin P50 and all of the variables that affect oxygen delivery. While our present knowledge may be inadequate to account for all such variables, this may be the time to shift our focus away from static hemoglobin levels to a more dynamic understanding of how different hemoglobin levels are used in different clinical situations to provide the life-sustaining oxygen delivery.

\section{References}

1 Fishbane S: What is needed to achieve a hemoglobin of 11.0-13.0 g/dl in end-stage renal disease. Blood Purif 2007;25:53-57.

2 Phrommintikul A, Haas SJ, Elsik M, Krum $\mathrm{H}$ : Mortality and target haemoglobin concentrations in anaemic patients with chronic kidney disease treated with erythropoietin: a meta-analysis. Lancet 2007;369:381-388.
3 Treger A, Shaw DB, Grover RF: Secondary polycythemia in adolescents at high altitude. J Lab Clin Med 1965;66:304-314.

4 Chanutin A, Hermann E: The interaction of organic and inorganic phosphates with hemoglobin. Arch Biochem Biophys 1969;131: $180-184$.

5 Diskin CJ, Stokes TJ, Dansby LM, Radcliff L, Carter TB: Can acidosis and hyperphosphataemia result in increased erythropoietin dosing in haemodialysis patients? Nephrology (Carlton) 2006;11:394-399.

\section{Reply}

\section{Steven Fishbane}

Winthrop University Hospital, Mineola, N.Y., USA

Sir,

I am in full agreement with the very sensible and wise comments of Dr. Diskin. It would be of great value to be able to assess more than just hemoglobin concentration to assess the impact of anemia and the effectiveness of erythropoiesis stimulating agent treatment. Some measure that could summate tissue exposure to hypoxia would be useful. Since the hypoxia-inducible factor-1 system is stimulated by hypoxia, any stable metabolites of this system might be suitable.

\section{KARGER}

Fax +4161306 1234 E-Mail karger@karger.ch www.karger.com
(C) 2007 S. Karger AG, Basel 0253-5068/07/0253-0280\$23.50/0

Accessible online at: www.karger.com/bpu
Charles J. Diskin, MD, HNDT

Auburn University, Bldg 21

121 N. 20th Street

Opelika, AL 36801 (USA)

Fax +1 334742 0242, E-Mail HNDT512@bellsouth.net 